\title{
CORRELAÇÃO DE DADOS DE ANÁLISE DE EMISSÃO VEICULAR ENTRE ANALISADOR FT-IR E MÉTODO TRADICIONAL PARA MEDIÇÃO DE ANALISE MODAL
}

\author{
Danilo Antônio Torres ${ }^{1}$, Marcelo Miyada Redígolo², Anderson Flores $^{2}$ \\ ${ }^{1}$ General Motors do Brasil, Indaiatuba, SP, Brazil \\ ${ }^{2}$ Embu Cientifica Ind e Com Ltda, Embu das Artes, SP, Brazil \\ danilo.torres@gm.com, marcelo@ecientifica.com.br, anderson@ecientifica.com.br
}

\section{RESUMO}

A análise dos gases de emissão é uma etapa essencial para o desenvolvimento de motores, tanto LDV (light duty vehicles), como HDV (heavy duty vehicles). O método tradicional de análise de emissões veiculares é custoso e limitado com relação à determinação de gases como $\mathrm{CH}_{4}, \mathrm{EtOH}$, aldeídos, entre outros. Nesse trabalho, foram correlacionados resultados obtidos com o analisador de gases de infravermelho por transformada de Fourier (FT-IR, Fourier Transform Infrared Spectrometry) e o método tradicional de análise modal. Foram determinados os gases $\mathrm{CO}, \mathrm{CO}_{2}, \mathrm{NO}_{\mathrm{X}}, \mathrm{EtOH}, \mathrm{CH}_{4}$ e aldeídos. Com base nos resultados obtidos, é possível afirmar que os dois métodos de análise apresentam desempenho semelhante. Sendo assim, é possível utilizar o FTIR para pesquisas durante o desenvolvimento, gerando redução de custo (manutenção reduzida e baixos tempos de parada) durante este trabalho, uma vez que o FT-IR não utiliza gases padrão para calibração, entre outros insumos necessários à análise modal.

\section{INTRODUÇÃO}

Para comercialização de um veículo no Brasil ou em qualquer país, uma montadora precisa passar por várias etapas até sua homologação e inicio de vendas. Umas destas etapas é o teste de certificação de emissões, o qual consiste em mostrar que o veículo atende os limites legais de emissões estabelecidos pelo órgão governamental responsável, no Brasil, o IBAMA.

Há várias etapas de desenvolvimento do veículo visando atender os limites legais até chegar à etapa de homologação, na qual é utilizada a norma NBR6601 [1] como metodologia e procedimento para teste de emissões. Para o desenvolvimento são utilizado métodos de análise de emissões antes do catalisador, entre os catalisadores (veículos com dois catalisadores), e após os catalisadores, segundo a segundo $(1 \mathrm{~Hz})$. Com os resultados obtidos, o engenheiro pode identificar onde e em qual condição o catalisador está com baixa eficiência, ajustando assim a melhor janela de catalisador, buscando a melhor relação custobenefício com relação ao catalisador utilizado e também a característica da calibração. 
Os equipamentos atualmente utilizados para tal medição segundo a segundo têm capacidade apenas para medição de hidrocarbonetos (HC), Monóxido de Carbono (CO), Óxido Nítrico $\left(\mathrm{NO}_{\mathrm{X}}\right)$ e Dióxido de Carbono $\left(\mathrm{CO}_{2}\right)$, não sendo capazes de determinarem gases como Metano $\left(\mathrm{CH}_{4}\right)$, Etanol (ETOH) e aldeídos.

Um método analítico que tem se destacado nos últimos anos é o infravermelho com transformada de Fourier (FT-IR, Fourier Transform Infrared) [2], capaz de analisar diversos gases simultaneamente: gases tradicionais como $\mathrm{HC}, \mathrm{CO}, \mathrm{NO}_{\mathrm{X}}$ e $\mathrm{CO}_{2}$, e também os gases não tradicionais, como $\mathrm{CH}_{4}$, ETOH, e aldeídos. Esse tipo de analisador apresenta alta precisão e exatidão e limites de detecção no nível sub-ppm para alguns gases, além de ser capaz de especiar hidrocarbonetos oxigenados e não oxigenados.

Atualmente, está sendo discutida a metodologia aplicada para desconto do Etanol não queimado em relação ao NMHC. Com o analisador FT-IR, pode-se identificar em qual momento do teste o veículo movido a etanol emite tal componente e, com esses dados, podese trabalhar na calibração ou modificação de hardware do veículo para que iniba ou até mesmo reduza tal poluente durante o funcionamento do motor. Como dito anteriormente, com métodos atuais isso é praticamente impossível, pois o método tradicional, conforme NBR 15598 [3], para análise deste componente é feito usualmente por fases, onde a concentração dos gases de emissão é determinada durante as fases 1, 2, 3, etc. $\mathrm{O}$ mesmo ocorre na determinação dos aldeídos, conforme norma NBR 12026 [4].

Neste trabalho iremos mostrar a diferença entre a medição segundo a segundo com o analisador FTIR comparado com medição segundo a segundo medido com métodos tradicionais existentes no mercado.

\section{O que é um teste de emissões veicular}

Para medição de emissões de um veículo em dinamômetro de chassis são utilizadas as seguintes normas: NBR 6601 (Medição das emissões de escapamento), NBR 12026 (Medição de emissões de aldeídos), NBR 15598 (Medição do etanol não queimado) e NBR 7024 (medição do consumo de combustível) [5].

Existe um ciclo de condução padrão, conforme descrito no NBR 6601, onde são executadas 3 fases, conforme descrito abaixo.

- Primeira fase ou fase fria: Partida do motor frio, duração de 505 segundos, percurso de $5.725 \mathrm{~km}$;

- Segunda fase ou fase estabilizada: duração de 866 segundos, percurso de 6.,200 $\mathrm{km}$;

- Terceira fase ou fase quente: Partida do motor a quente, sendo o ciclo e seu percurso similar ao da primeira fase. 


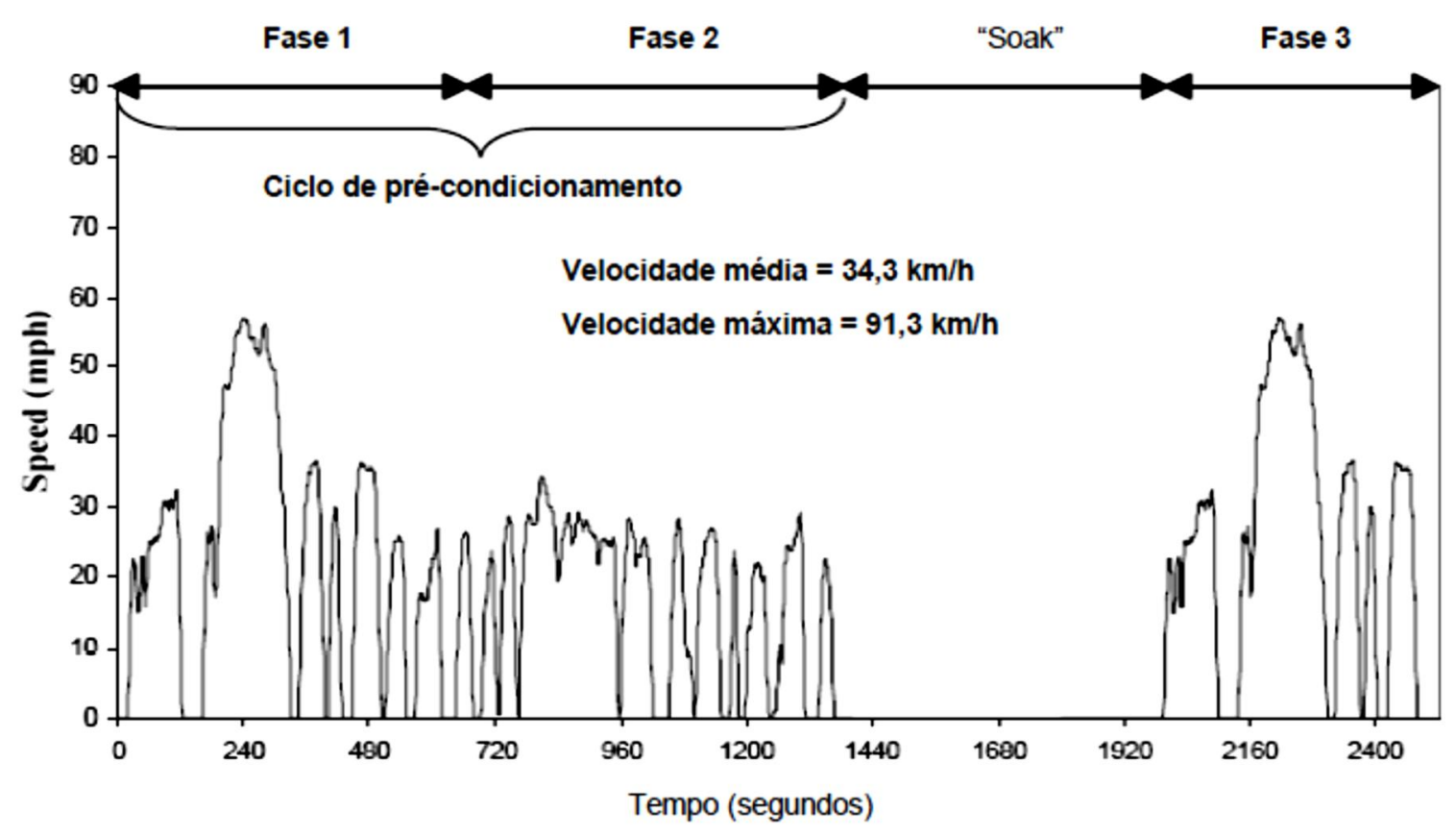

Figura 1. Ciclo de condução conforme NBR 6601

Durante o ensaio de um teste de emissões, a poluição gerada pelo veículo durante o ciclo citado na figura 1 .

Conforme descrito na NBR 6601, cada fase do teste é coletada em dois balões: um balão coleta o ar de diluição e o outro coleta o gás diluído do escapamento do veículo. Esta coleta é feita por um sistema de amostragem de volume constante. Após o termino de cada fase, são analisados os poluentes $\mathrm{HC}, \mathrm{CH}_{4}, \mathrm{CO}, \mathrm{NO}_{\mathrm{X}}, \mathrm{CO}_{2}$, com o auxílio de um software de automação, que faz os cálculos e exibe os resultados conforme descrito na norma em questão.

Lembrando que o teste, conforme NBR 6601, é executado em um laboratório com temperatura, umidade e pressão controlados.

\section{Método de analise segundo a segundo bruta ou diluída atual}

Atualmente, a análise segundo a segundo (modal) das emissões de veículo é feita por uma bancada de emissões composta por analisador de HC do tipo FID (Flame Ionisation Detector), analisador de $\mathrm{CO}$ e $\mathrm{CO}_{2}$ do tipo NDIR (Nondispersive Infrared) e $\mathrm{NO}_{\mathrm{X}}$ do tipo CLD (Chemiluminescent Detector), com bomba para amostragem e regulador de vazão [6]. Alguns sistemas possuem métodos para diluição da amostra, ou seja, a amostra do veículo é diluída geralmente em gás nitrogênio para que os gases padrão dos analisadores sejam iguais ao da bancada bag trazendo certa redução de custo em relação à quantidade de cilindros alocados para efetuar a calibração dos analisadores, mas, na maioria dos casos, esse módulo de diluição não existe, fazendo com que o laboratório necessite de uma quantidade maior de gases padrão, pois cada analisador geralmente utiliza 3 ou 4 faixas diferentes de concentração para calibração. 
$\mathrm{Na}$ figura 2 observa-se um breve diagrama de uma bancada tradicional de coleta de emissões segundo a segundo.

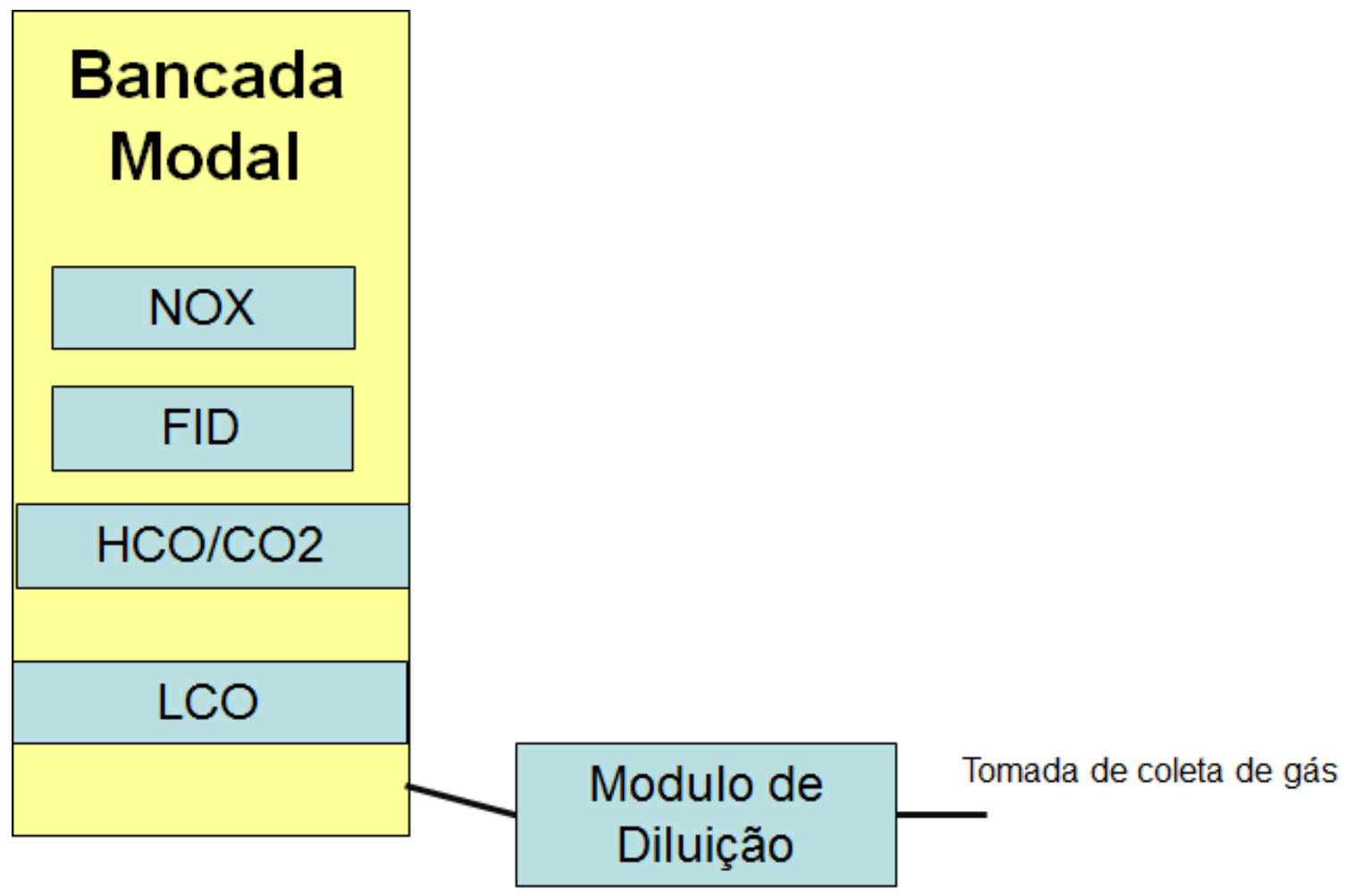

Figura 2. Bancada de analise modal

\section{Principio de funcionamento e aplicação do FTIR para analise modal}

A técnica analítica de infravermelho utiliza a vibração molecular característica de cada gás presente na amostra para identificá-los. $\mathrm{O}$ analisador FTIR utilizado neste trabalho foi o modelo MG2030 da MKS Instruments Inc. [7]. O analisador determina até 30 gases simultaneamente utilizando calibrações fixas, desonerando completamente 0 usuário do uso de gases de calibração. A montagem num chassi anti-choque e a linearização constante do detector de estado sólido MCT (telureto de mercúrio cádmio) propicia alta resolução e limites de detecção menores que $20 \mathrm{ppb} \mathrm{em}$ amostras com até $30 \%$ de umidade. A análise quantitativa é realizada utilizando o método dos mínimos quadrados clássicos, que apresenta vantagens como a quantificação de gases em amostras complexas (diversos gases presentes) e fácil diferenciação espectral (remoção de picos de interferentes como $\mathrm{H}_{2} \mathrm{O}$ ). A célula de gás de volume reduzido $(200 \mathrm{~mL})$ reduz a perda de amostra.

Para uma análise modal de emissões de um veículo utilizando o FTIR, é necessário um sistema de amostragem composto por uma bomba de fluxo constante, linha aquecida e filtro para remoção de partículas da amostra. Veículos movidos a Etanol podem requerer uma unidade de remoção da água quando a umidade da amostra for superior a $30 \%$. 


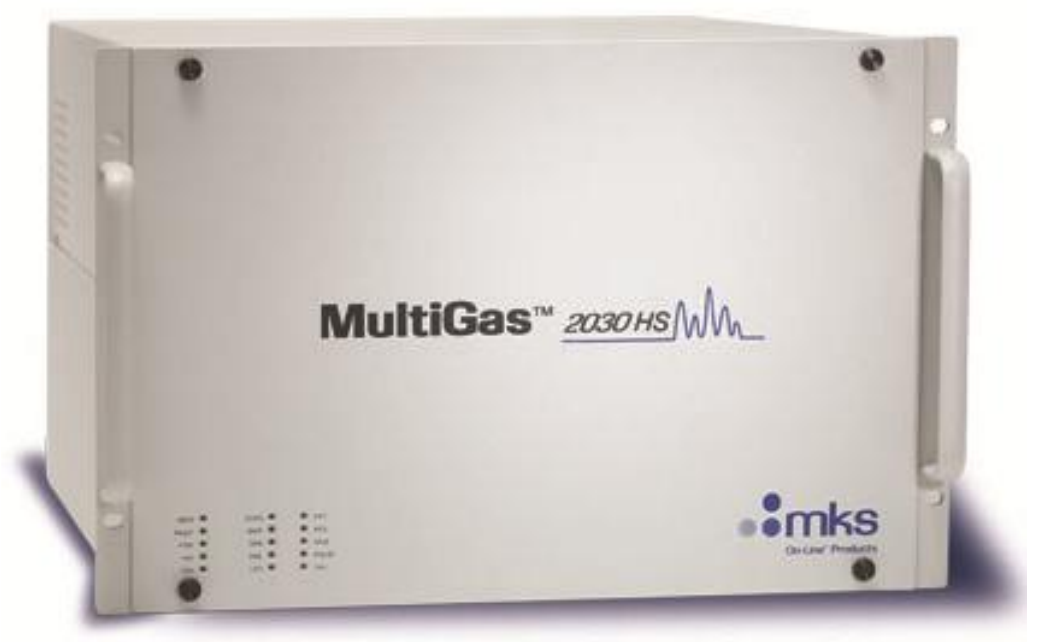

Figura 3. Detector de um FTIR

\subsection{Verificação e manutenção de um analisador FTIR}

O FTIR é um analisador quem possui receitas pré-ajustadas de fábrica, sendo necessária apenas checagem periódica do seu desempenho. A checagem pode ser realizada utilizando um cilindro de gás padrão com a concentração e componente que se deseja checar, bastando injetar o gás padrão no ponto de coleta e verificar o valor medido pelo FTIR, comparando assim com o valor do gás padrão. Este procedimento é feito a critério de cada usuário, não havendo obrigatoriedade quanto à periodicidade do mesmo.

A manutenção do analisador FTIR é de baixo custo, sendo apenas necessária a troca do filtro da bomba quando o mesmo está com restrição, limpeza da linha aquecida conforme critério do usuário, e a limpeza da célula de gás, que requer solução de peróxido de hidrogênio e linha de ar comprimido.

Um item importante para o funcionamento de um analisador FTIR é o nitrogênio liquido utilizado para refrigerar o detector MCT, assim como nitrogênio gasoso para purga e limpeza do detector antes da execução do ensaio e enquanto o analisador está em espera.

\subsection{Metodologia de Ensaio comparativo e condições ambientais}

Para este estudo comparativo entre o FTIR e o método tradicional de coleta de análise segundo a segundo do gás do escapamento do veículo, foram executados vários testes de emissões, conforme NBR 6601, em dinamômetro de chassis, com diferentes combustíveis como, por exemplo, Etanol, Gasolina com várias porcentagens de Etanol, gasolina pura e diesel S10. Os resultados com todos os combustíveis citados apresentaram o mesmo comportamento quando se compara a diferença entre os métodos. 
Tanto a bancada tradicional de emissões quanto o FTIR coletaram o gás do escapamento do veículo após os catalisadores simultaneamente.

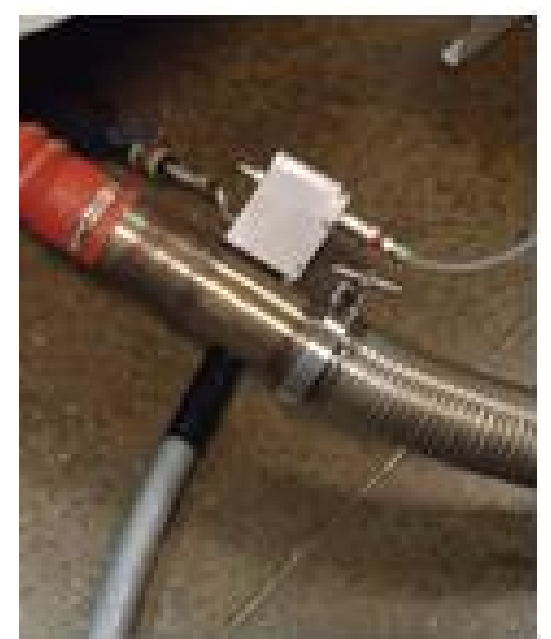

Figura 5. Tomadas de coleta FTIR e bancada tradicional

Os ensaios foram realizados no laboratório de emissões da General Motors do Brasil, situado em Indaiatuba - SP, com temperatura, umidade e pressão barométrica controlados conforme descrito na norma NBR 6601.

\section{Resultados}

Apresentam-se a seguir os resultados de um teste com veículo abastecido com etanol. Nos gráficos foram mantidos apenas os 500 segundos iniciais do ciclo conforme NBR 6601. Nas figuras de 6 a 9 são apresentados os resultados em ppm para o analisador FT-IR e a bancada tradicional. A figura 10 apresenta os resultados do analisador FTIR, uma vez que aqueles gases não podem ser medidos pela bancada tradicional.

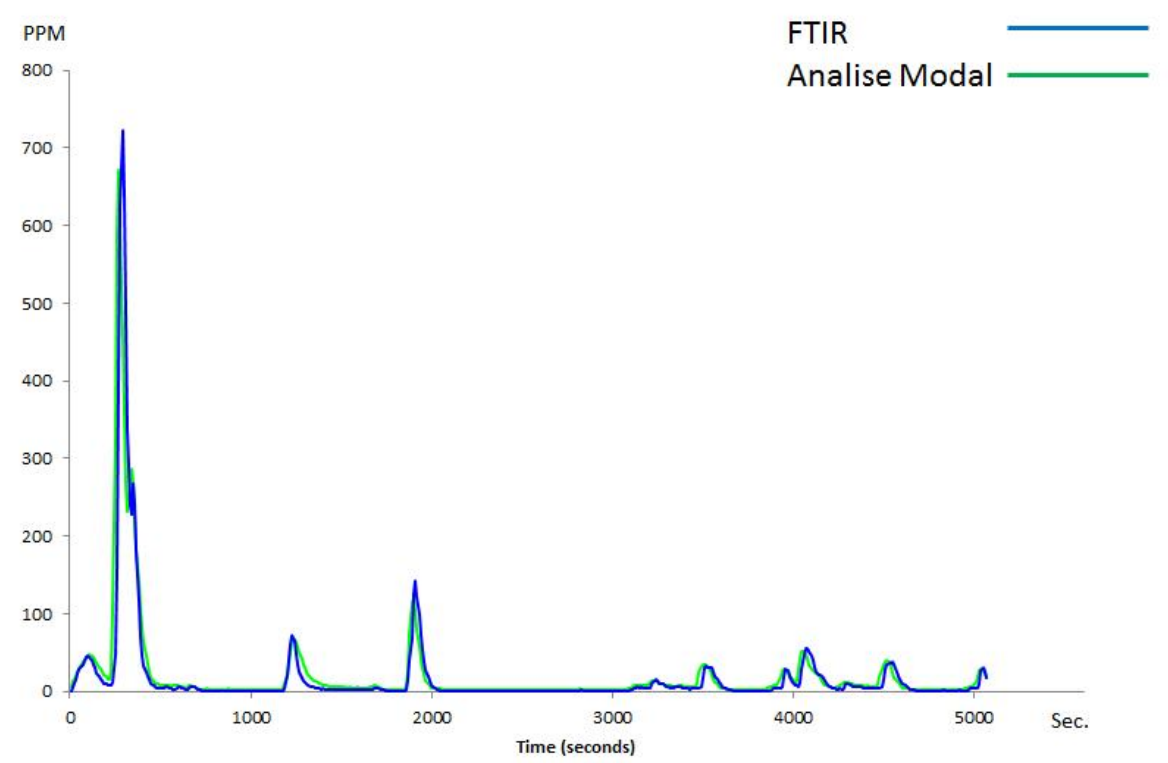

Figura 6. Análise de $\mathrm{NO}_{\mathrm{X}}$ 


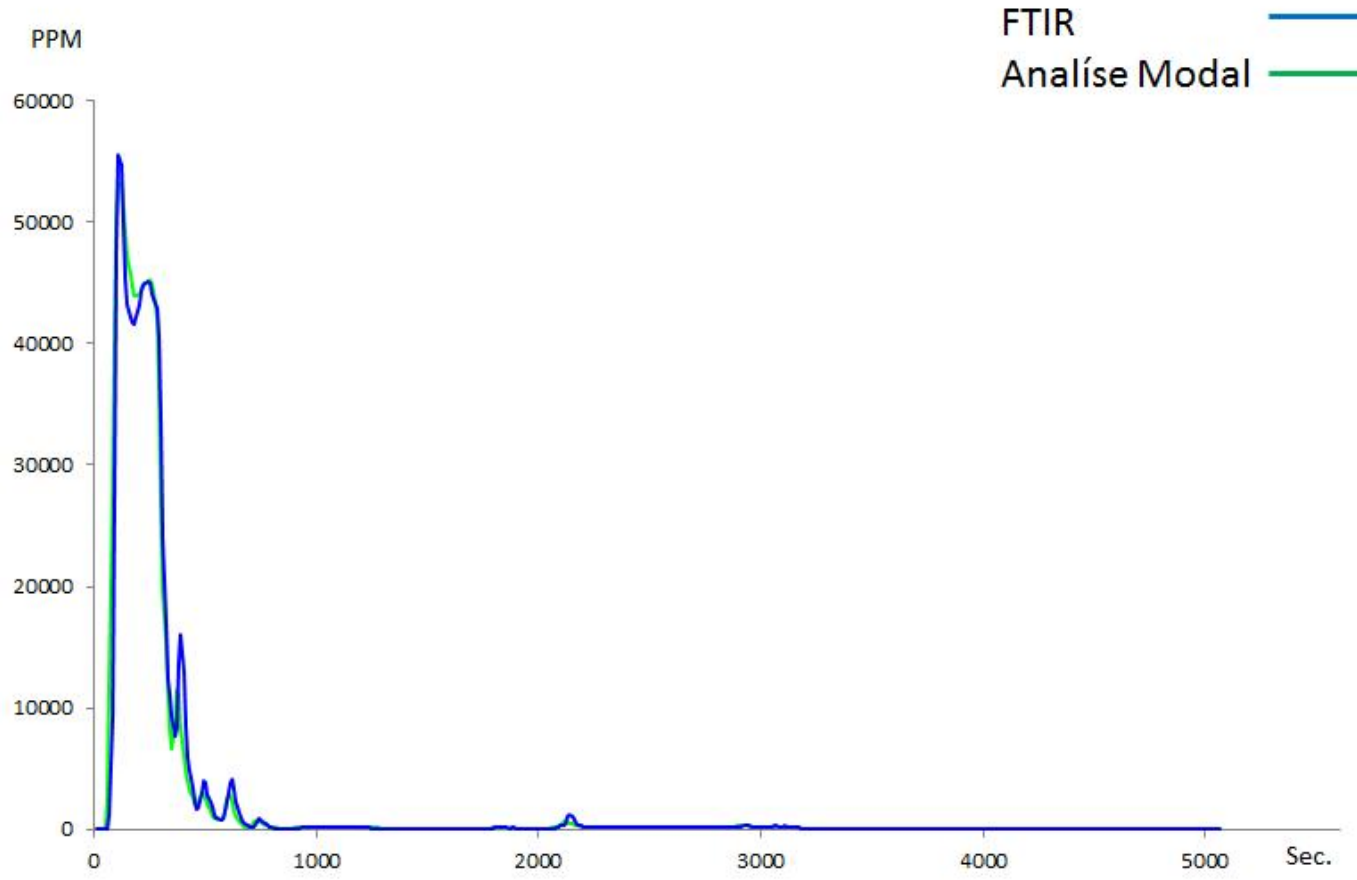

Figura 7. Análise de CO

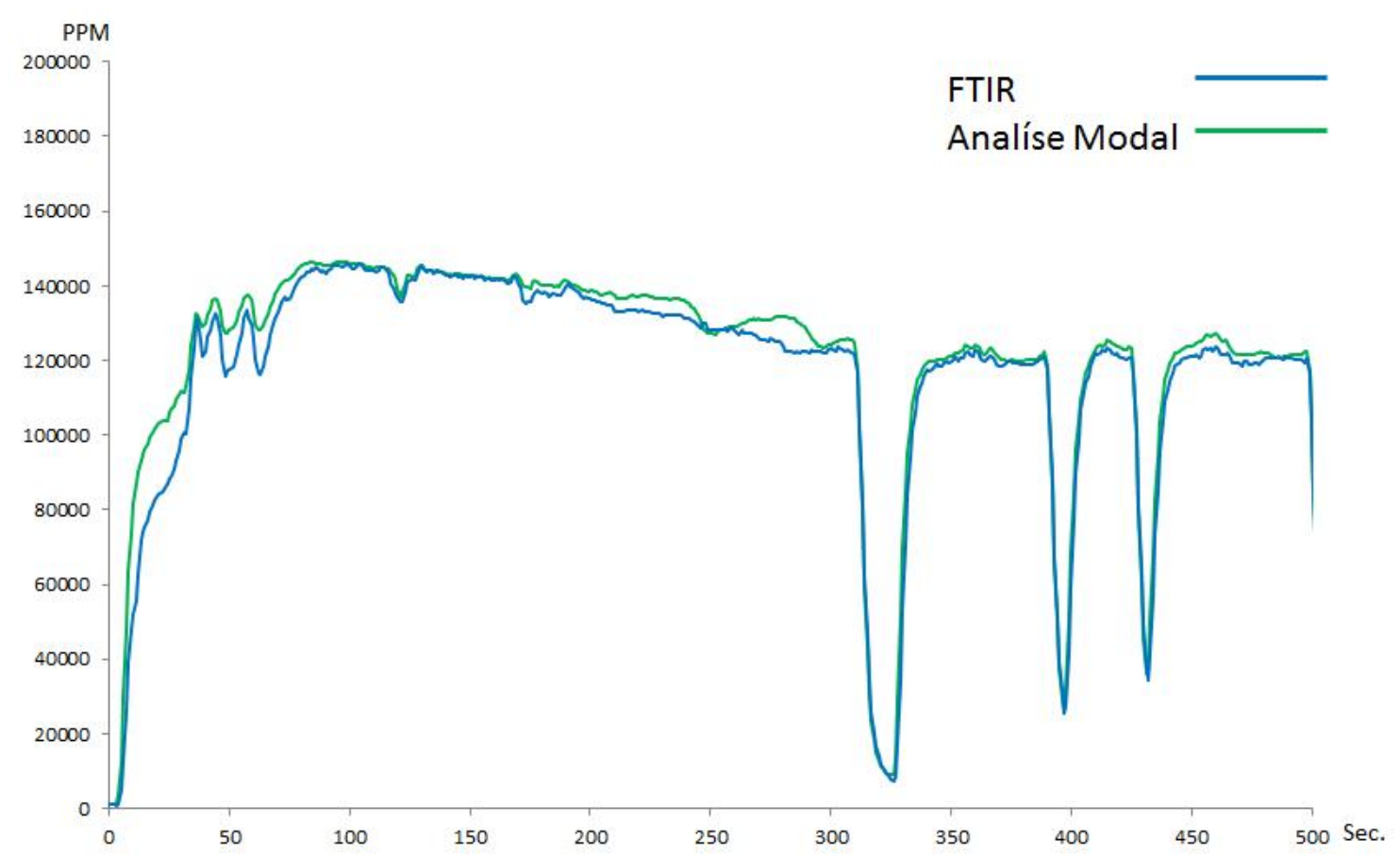

Figura 8. Análise de $\mathrm{CO}_{2}$ 


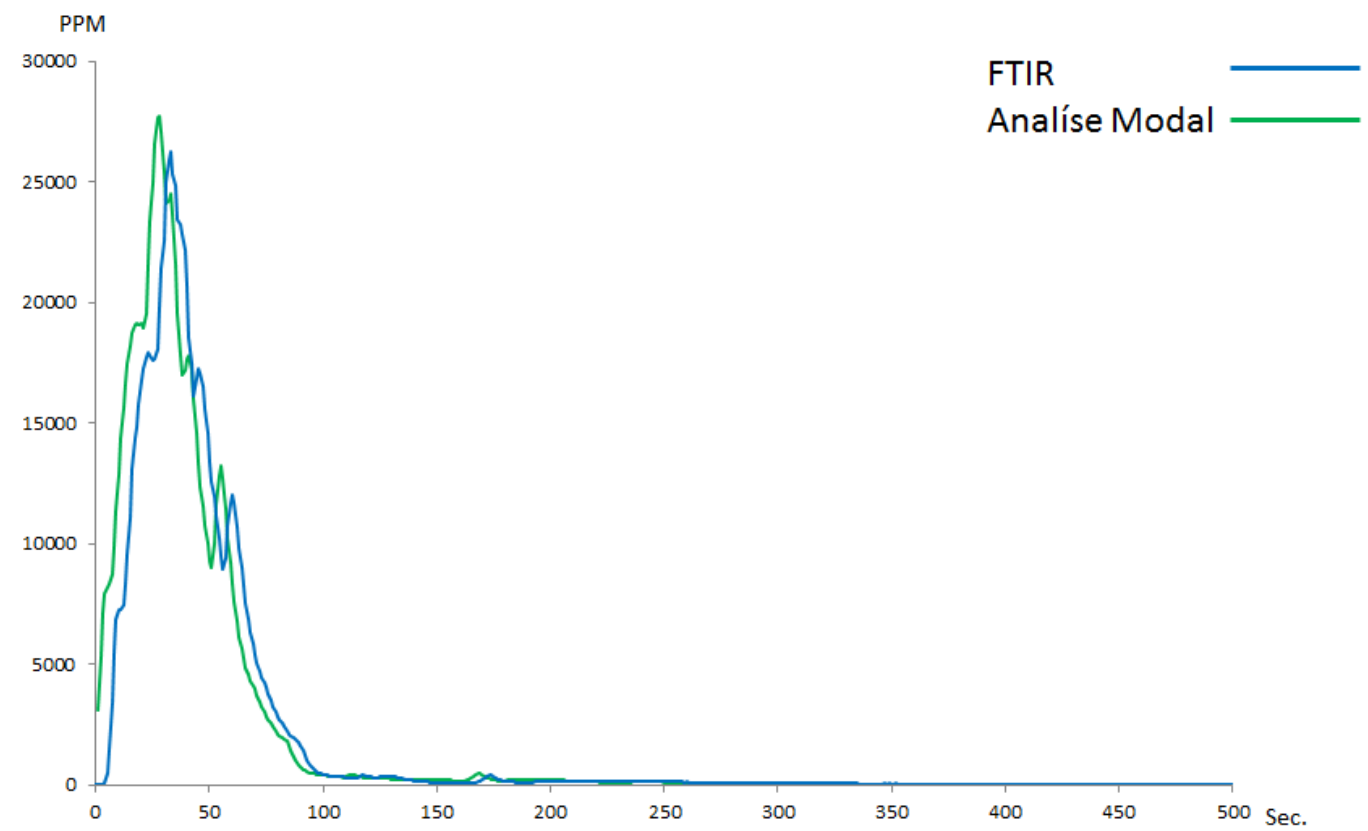

Figura 9. Análise de HC

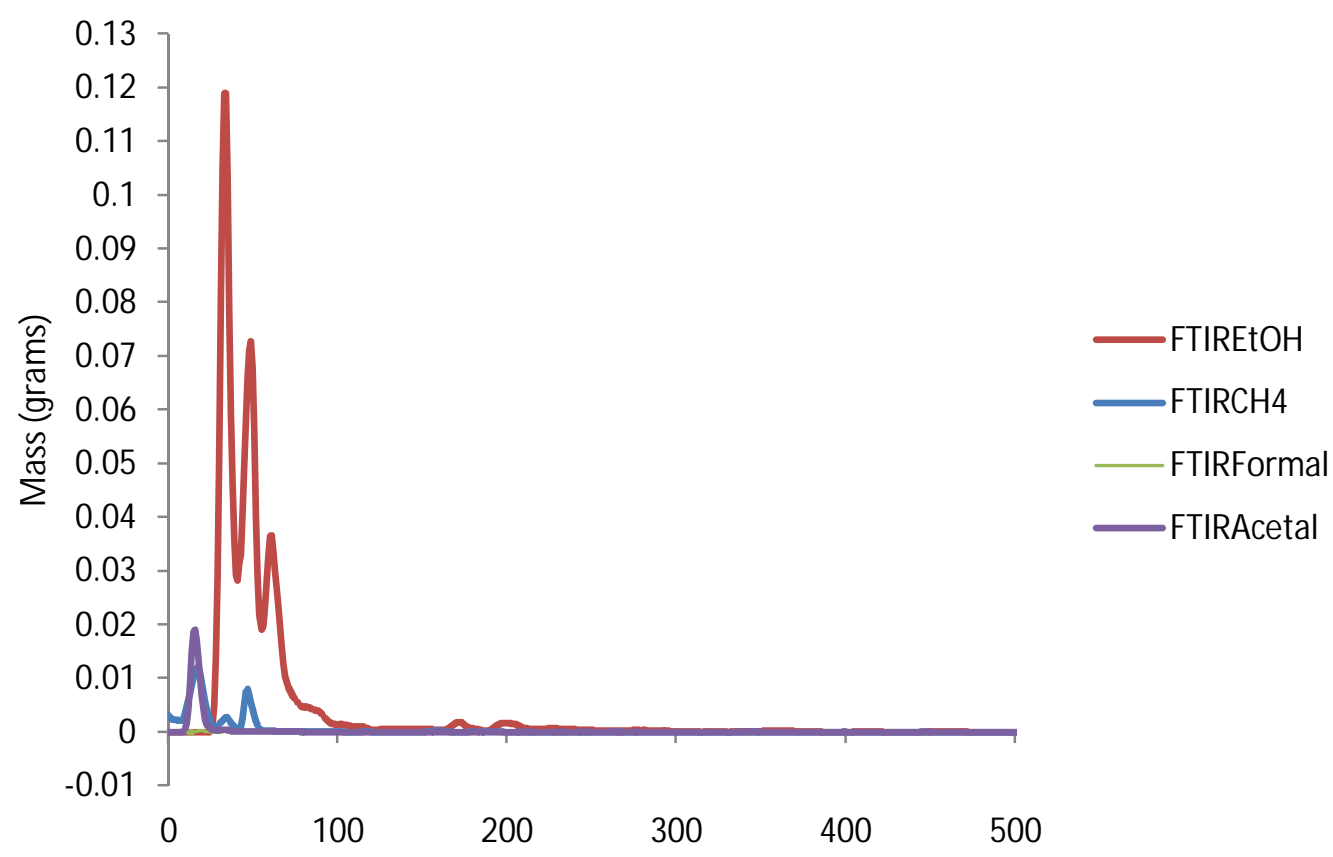

Figura 10. Determinação de ETOH, CH4, Formaldeído e Acetaldeído pelo FTIR

A seguir são apresentados os resultados da análise de erro relativo percentual entre as determinações do analisador de FT-IR e o analisador tradicional. 
Tabela 1. Erro relativo percentual entre FT-IR e o analisador tradicional

\begin{tabular}{cc}
\hline Gás & $\begin{array}{c}\text { Erro relativo } \\
\text { (FT-IR x analisador tradicional) }\end{array}$ \\
\hline NOx & $10 \%$ \\
CO & $10 \%$ \\
CO2 & $5 \%$ \\
HC & $10 \%$ \\
ETOH & $10 \%$ \\
Formaldeído & $10 \%$ \\
Acetaldeído & $10 \%$ \\
Metano & $10 \%$ \\
\hline
\end{tabular}

É possível observar que o analisador FTIR é muito confiável, apresentando erro relativo entre $5 \%$ à $10 \%$ para todos os gases comparados com o método tradicional de medição. Além disso, o analisador FT-IR é capaz de determinar segundo a segundo etanol não queimado, metano, formaldeído e acetaldeído, conforme Figura 10.

\section{Conclusão}

Com base neste estudo, pode-se afirma que o analisador FTIR pode auxiliar na tomada de decisões durante o desenvolvimento de um veículo, assim como o método tradicional para analise modal.

Ademais, o FTIR é capaz de determinar gases não tradicionais como Etanol não queimado, formaldeído, acetaldeído, oferecendo assim uma nova ferramenta não disponível em nenhuma bancada de emissões tradicional.

Desta forma, é possível considerar os seguintes pontos a favor do FTIR:

- FTIR é um analisador robusto, de simples operação e manutenção, o que o torna bastante econômico.

- Substituindo o método de analise modal tradicional pelo FTIR, pode-se gerar uma redução de custo em relação a gases de calibração, energia elétrica e tempo de manutenção.

Vale salientar que o FTIR não utiliza nenhum gás padrão durante o ensaio, e também não precisa de nenhum modulo de diluição da amostra bruta do veículo, sendo assim um equipamento de simples manutenção, detecção de problema (troubleshooting), rápida manutenção preventiva e baixo custo estrutural. 


\section{Referências}

[1] ABNT. NBR 6601 - Veículos rodoviários automotores leves - Determinação de hidrocarbonetos, monóxido de carbono, óxido de nitrogênio, dióxido de carbono e material particulado no gás de escapamento. Ed. atual. Brasil: ABNT, 2012.

[2] SPARTZ, Martin, Infrared analysis of E85 engines, Automotive Testing Technology International, 77 - 78, Março, 2008.

[3] ABNT. NBR 15598 - Veículos rodoviários automotores leves - Determinação de etanol não queimado contido no gás de escapamento, por cromatografia gasosa Método de ensaio: ABNT, 2008.

[4] ABNT. NBR 12026 - Veículos rodoviários automotores leves - Determinação de aldeídos e cetonas contidos no gás de escapamento, por cromatografia líquida Método DNPH. Ed. atual Brasil: ABNT, 2009.

[5] ABNT NBR 7024 - Medição do consumo de combustível. Ed. atual. Brasil: ABNT, 2006.

[6] AVL: AVL Emission test systems, rev. 01.

[7] MKS: MultiGas Analyzer Models 2030, 2031 and 2032 Hardware Manual, rev. D. 